\title{
Health-related quality of life in southern Iranian rural women: a multivariate multilevel study
}

\author{
This article was published in the following Dove Press journal: \\ International Journal of Women's Health \\ 10 February 2015 \\ Number of times this article has been viewed
}

\author{
Seyed Mohammad Taghi \\ Ayatollahi \\ Najaf Zare \\ Tania Dehesh
}

Department of Biostatistics, School of Medicine, Shiraz University of Medical Sciences, Shiraz, Iran
Correspondence: Tania Dehesh Department of Biostatistics, School of Medicine, Shiraz University of Medical Sciences, PO Box 7/345-I874,

Shiraz, Iran

Tel +98 7II 6258645

Fax +98 7II 2349330

Email tania_dehesh@yahoo.com/

dehesht@sums.ac.ir
Purpose: The evaluation of health-related quality of life (HRQOL) is increasingly growing to be of much significance. In an attempt to improve the agricultural conditions and to prevent the rural-urban migration, analyzing HRQOL in rural communities has gained significant governmental attention. The purpose of this study was initially to investigate rural women's HRQOL, and then to assess the influence of some specific covariates on four domains of rural women's HRQOL via multivariate analysis (MA) and multivariate multilevel analysis (MMA), and finally to compare the results.

Methods: Out of 146 active health centers in villages around Shiraz, Iran, ten health centers were selected, using a multistage random sampling process. These ten health centers covered 18 villages. In this cross-sectional study, all women over the age of 15 in a sample of 1,128 rural residents were interviewed using a brief version of the World Health Organization HRQOL (the WHOQOL-BREF) questionnaire. Assessing the influence of some specific covariates on the four domains of rural women's HRQOL was conducted by MA and MMA.

Results: The average range for all four domain scores was between 12.53 and 14.27, which indicates that HRQOL for rural women is acceptable on the whole. The social relations domain and the environmental domain received the highest (14.3 $\pm 2.5 \mathrm{SD})$ and the lowest (12.5 $\pm 2.3 \mathrm{SD})$ scores respectively. Marital status did not indicate any significant effects on MA, but it presented an important influence on MMA. Furthermore, age and chronic diseases showed indifferent levels of significance in the two analytical methods.

Conclusion: Rural women are in need of more heedfulness during their lives, especially about facilities and health. MMA is a more accurate procedure in exploring the important covariates in HRQOL.

Keywords: Health-related quality of life, multivariate multilevel analysis, multivariate analysis, rural women

\section{Introduction}

Since the 1940s, as the World Health Organization (WHO) began to emphasize that health consists of physical, mental, and social well-being and not only the absence of diseases, life quality evaluation has gained more importance. ${ }^{1}$ Health-related quality of life (HRQOL) includes a variety of aspects such as health status, physical activities, psychosocial modification, and life satisfaction. These concepts are relevant to cultural, political, and economic status of communities. ${ }^{2}$ The WHO defines HRQOL as an individual perception of an individual's position in life in the context of cultural and value systems in which he/she lives, and in relation to ambitions, expectations, standards, and concerns. ${ }^{3}$

HRQOL is an important consideration in choosing an area in which to reside; certainly, people tend to move to communities of higher HRQOL. ${ }^{4}$ Education and employment are the two most important motivational factors in rural migration to cities and urban areas. ${ }^{5}$ 
There is a direct relationship between quality of life and agricultural industry in rural areas. ${ }^{6}$ Women play a significant role in promoting their family's quality of life, and this is due to their emotional attachment to their family members. HRQOL in the rural setting is determined by the impacts of numerous factors like housing, location, transportation, income, standard of living, and physical and social environment. ${ }^{7,8}$

Iran's population is reported to be over 75 million people, and $30.92 \%$ reside in rural areas. ${ }^{9}$ Unfortunately, there are no real statistics available on women's living conditions in rural areas, and there is a lack of information about HRQOL and rural women's needs, mostly due to their illiteracy and lack of government support. In order to prevent rural migration to the cities, the HRQOL analysis in rural communities has to gain more governmental attention. ${ }^{10}$

The brief version of the WHO HRQOL (WHOQOLBREF), a shortened version of the WHOQOL-100, is a generic HRQOL measurement tool. A Persian version of the WHOQOL-BREF has been developed and is believed to be a tool of excellent reliability and validity. ${ }^{11}$

Certainly, a lot of covariates affect HRQOL, and their impacts on HRQOL have been checked in many studies, ${ }^{12,13}$ and in most of these studies, the effects of these covariates were assessed for each domain score separately. ${ }^{14,15}$ In fact, some covariates that have effects on HRQOL include age, sex, education, living condition, and employment status. Thus, evaluating HRQOL with multivariate procedures is a valid approach. Assessment of common individual covariates that affect the four domains of HRQOL simultaneously allowed the greatest gains in knowledge when applying multivariate analysis (MA) and also multivariate multilevel analysis (MMA) in this study.

Since the four domain scores are correlated, using MA may offer more precision in assessing the effect of covariates on HRQOL than a univariate analysis. Therefore, the MA and MMA were used in this study to assess the association between the four domain scores and the same covariates for more precision.

The aims of this study were: 1) to investigate rural women's HRQOL in southern Iran; 2) to simultaneously assess influential factors such as individualism and social covariates on four domains of rural women's HRQOL by using MA and MMA; and 3) to compare the results.

\section{Materials and methods}

Out of 146 active health centers in Shiraz villages, ten health centers were selected for inclusion through a multistage random sampling process. These ten health centers covered 18 villages. In these 18 villages, 1,128 women between the ages of 15 and 49 years were interviewed in this crosssectional study. Most of the women were interviewed, due to their illiteracy, by an expert interviewer, and those women who were able to complete the questionnaire, did so. These populations were found to be representative of rural women's communities in Shiraz, southern Iran. All respondents were informed about the objectives of this study, and their participation in this study was completely on a volunteer basis. This study also complies with Helsinki declaration.

The WHO has executed a project on developing an assessment questionnaire for HRQOL since the early 1990s. They first attempted to develop a questionnaire containing 100 questions (WHOQOL-100) on the importance of some aspects of life and the effect of these aspects on the respondent's HRQOL. The most suitable questions were selected and used to create a brief version (WHOQOL-BREF) after further analysis. ${ }^{16,17}$

Like the original WHOQOL-BREF, the Persian version of the WHOQOL-BREF questionnaire contains 26 items. It is worth mentioning that the first two items on the questionnaire are of general health and HRQOL and have not been taken in to consideration for the domain score calculation. The other 24 items combine four domains: 1) physical capacity (7 items); 2) psychological well-being (6 items); 3) social relationship (3 items); and 4) environment (8 items). All items were rated on a 5-point scale. There is no overall score for the WHOQOL-BREF, and each domain score was calculated by multiplying the means of all domains' items by a factor of four. All domains' scores ranged from 4 to 20 points, a higher score indicating a higher HRQOL. The two first items of the overall HRQOL score and general health were calculated in a similar manner to the domain scoring method. When more than two items were missed (not answered) in a domain, its score was not calculated; however, for the social relationship domain, if more than one item was missed, it was completely invalidated.

Rural women's domain scores could be considered as multiple outcomes, nested within an individual's outcome, and individuals nested within villages' outcomes. In this study, we have three levels, rural women's domain scores or outcomes as level one, rural woman as level two, and villages as level three. These levels are depicted in Figure 1. The results of these two analyses were also compared. For a detailed description of the analysis procedure, refer to previous literature. ${ }^{18,19}$ While there have been many studies that have investigated HRQOL, 


\section{Level 3: villages}

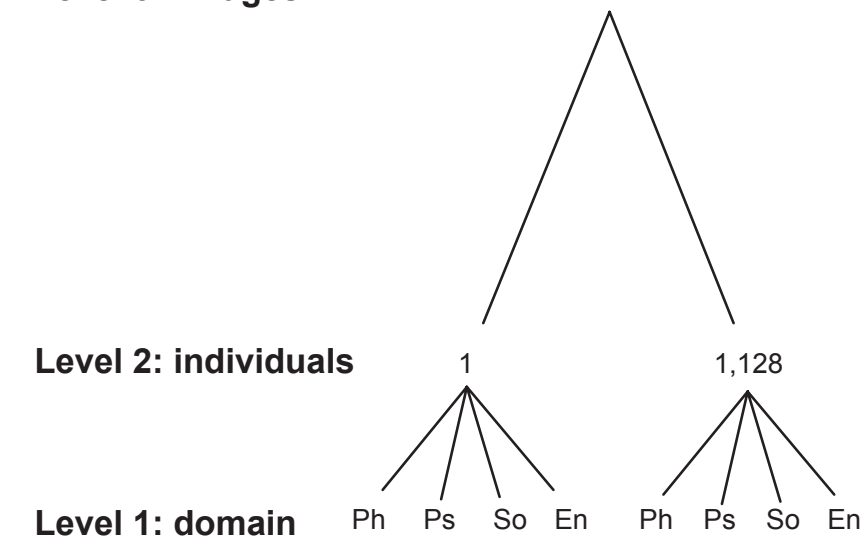

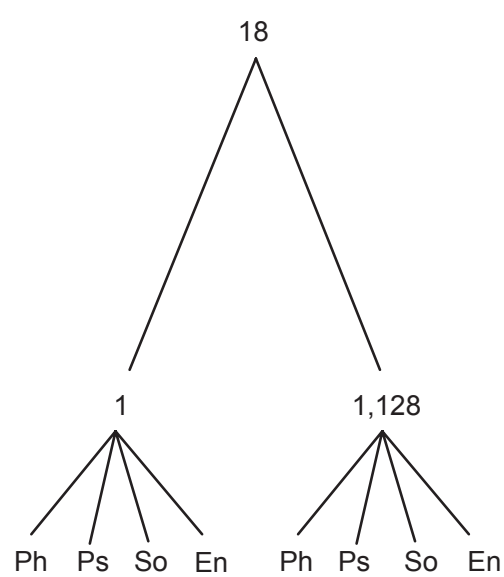

Figure I Multivariate multilevel structure of domain scores (Ph, Ps, So, and En) at level I nested within individuals at level 2 and further nested within villages at level 3. Abbreviations: Ph, physical domain; Ps, psychological domain; So, social relationship domain; En, environmental domain.

we are not aware of any study that has shown how individual demographic variables predict these four aspects (domains) of HRQOL simultaneously. The multilevel framework makes it possible to assess whether villages made a difference to individual HRQOL. In our model, the intercept was specified as a random variable in levels two and three. Estimated correlation between the four domains' scores at levels two and three is another advantage of using multivariate multilevel modeling. For MMA, the software package MLwiN (version 2.0) was used. The computations of multivariate results were performed by using SPSS (version 16.0).

\section{Results}

The participants' characteristics are shown in Table 1 based on three levels (outcomes, individuals, and villages). For the total sample of women $(n=1,128)$, the mean age was $31.6( \pm 8.2)$ years, so our sample pool was fairly young. Domain scores show that the domain of social relationships has the highest average score, and the environmental domain has the lowest score among rural people. As we can see in Table 1, despite the young population, approximately $13.8 \%$ of participants suffered from chronic illnesses. In our sample, the majority of women were married and illiterate.

Table 2 illustrates the results of MA and the effects of covariates on rural women's HRQOL. It also presents the mean and standard errors of HRQOL scores between different layers. MA showed that only chronic illness has a significant effect on the environmental domain. Health has a significant effect on physical and psychological domain scores.

Table 3 presents the MMA results. As we can see, chronic illness has a significant effect on two domain scores, physical capacity (beta coefficient $[\beta]=0.654 ; P<0.005$ ) and the psychological domain $(\beta=0.494 ; P<0.005)$, similar to the results presented in Table 2 that are based on MA. People who did not have a chronic illness reported higher HRQOL, again similar to MA analysis (Table 2). Age was not linearly associated with each of the four domains. Marital status had a positive significant effect on the physical capacity score $(\beta=1.387 ; P<0.005)$, in contrast to the social relationship score $(\beta=-2.835$; $P<0.005)$. The single women's physical capacity scores were close to scores of those who were married $(\beta=1.378 ; P<0.005)$. In other domain scores, marital status did not play a significant role between the individual outcomes. We saw no significant effect of educational accomplishment on HRQOL.

Table I Descriptive information on individual samples in three levels

\begin{tabular}{|c|c|c|}
\hline & Descriptor & Value \\
\hline \multicolumn{3}{|c|}{ Level I: multivariate outcome ( $n=4,5 \mid 2$ domain units) } \\
\hline Physical & Mean (SD) & I2.7| (I.5) \\
\hline Psychological & Mean (SD) & $13.28(2)$ \\
\hline Social relationship & Mean (SD) & $14.27(2.5)$ \\
\hline Environmental & Mean (SD) & $12.53(2.3)$ \\
\hline \multicolumn{3}{|c|}{ Level 2: individual ( $\mathrm{n}=1,128$ individuals) } \\
\hline \multirow[t]{2}{*}{ Chronic illness } & Yes, N (\%) & $156(13.8)$ \\
\hline & No, N (\%) & $972(86.2)$ \\
\hline Age, year & Mean (SD) & $31.6(8.2)$ \\
\hline \multirow[t]{3}{*}{ Marital status } & Single, N (\%) & II (I) \\
\hline & Married, N (\%) & $\mathrm{I}, 065(94.4)$ \\
\hline & Separated or widowed, N (\%) & $52(4.6)$ \\
\hline \multirow[t]{3}{*}{ Education } & Illiterate and primary school, N (\%) & $753(66.8)$ \\
\hline & High school, N (\%) & $359(31.8)$ \\
\hline & University, N (\%) & $16(14)$ \\
\hline Level 3: villages & Total villages, $\mathrm{n}$ & 18 \\
\hline
\end{tabular}

Abbreviations: $\mathrm{N}$, number of women; SD, standard deviation. 
Table 2 MA: associations between the four domain scores and covariates

\begin{tabular}{|c|c|c|c|c|c|c|c|c|}
\hline & \multicolumn{2}{|c|}{ Physical domain } & \multicolumn{2}{|c|}{$\begin{array}{l}\text { Psychological } \\
\text { domain }\end{array}$} & \multicolumn{2}{|c|}{$\begin{array}{l}\text { Social relationship } \\
\text { domain }\end{array}$} & \multicolumn{2}{|c|}{$\begin{array}{l}\text { Environmental } \\
\text { domain }\end{array}$} \\
\hline & Mean (SD) & $P$-value & Mean (SD) & $P$-value & Mean (SD) & $P$-value & Mean (SD) & $P$-value \\
\hline \multicolumn{9}{|l|}{ Disease status } \\
\hline Chronic illness & $12.46(1.7)$ & 0.85 & I $2.8(2.07)$ & 0.67 & I 3.98 (2.59) & 0.25 & II.98 (2.34) & 0.91 \\
\hline Healthy, N & $12.75(1.42)$ & & 13.35 (I.9) & & $14.34(2.47)$ & & $|2.6|(2.32)$ & \\
\hline Age, years & & $0.001 *$ & & $0.03^{*}$ & & 0.08 & & 0.23 \\
\hline \multicolumn{9}{|l|}{ Married status } \\
\hline Single, $N$ & $12.23(1.02)$ & 0.54 & 13.47 (I.9) & 0.47 & $14.8(1.47)$ & 0.77 & $12(2.4)$ & 0.22 \\
\hline Married, N & $12.70(1.46)$ & & $13.26(2)$ & & 14.26 (2.49) & & $12.53(2.33)$ & \\
\hline Widowed, N & $12.94(1.65)$ & & $13.65(1.97)$ & & $14.2(2.75)$ & & $12.5(2.3)$ & \\
\hline \multicolumn{9}{|l|}{ Education } \\
\hline Illiterate, $\mathrm{N}$ & I2.64 (I.45) & 0.54 & $13.12(1.98)$ & 0.94 & $14.08(2.5)$ & 0.49 & $|2.3|(2.26)$ & 0.44 \\
\hline High school, N & $12.85(1.48)$ & & $13.55(1.98)$ & & $|4.6|(2.4)$ & & $12.9 \mid(2.42)$ & \\
\hline University, N & $12.23(1.02)$ & & 14.56 (2.19) & & I5.II (2.8) & & $14.13(1.85)$ & \\
\hline
\end{tabular}

Note: $* p<0.05$

Abbreviations: MA, multivariate analysis; N, number of women; SD, standard deviation.

Table 3 MMA: associations between independent variables and the four domain scores

\begin{tabular}{|c|c|c|c|c|c|c|c|c|}
\hline & \multicolumn{2}{|c|}{ Physical domain } & \multicolumn{2}{|c|}{$\begin{array}{l}\text { Psychological } \\
\text { domain }\end{array}$} & \multicolumn{2}{|c|}{$\begin{array}{l}\text { Social relationship } \\
\text { domain }\end{array}$} & \multicolumn{2}{|c|}{$\begin{array}{l}\text { Environmental } \\
\text { domain }\end{array}$} \\
\hline & $\beta$ & $P$-value & $\beta$ & $P$-value & $\beta$ & $P$-value & $\beta$ & $P$-value \\
\hline Chronic illness, no vs yes & 0.49 & $0.04 *$ & 0.65 & $0.04 *$ & 0.21 & 0.65 & 0.45 & 0.25 \\
\hline Age, years & -0.007 & 0.38 & 0.010 & 0.32 & -0.014 & 0.22 & 0.01 & 0.23 \\
\hline \multicolumn{9}{|c|}{ Marital status, separated vs widowed } \\
\hline Single & 1.38 & 0.06 & 0.72 & 0.46 & 0.81 & 0.51 & 1.57 & 0.12 \\
\hline Married & 1.39 & 0.09 & 0.02 & 0.11 & -2.84 & 0.04 & 0.76 & 0.51 \\
\hline \multicolumn{9}{|c|}{ Education, illiterate and primary school vs high school and university } \\
\hline High school & 0.20 & 0.34 & 0.09 & 0.72 & 0.15 & 0.72 & 0.47 & 0.16 \\
\hline University & -0.53 & 0.37 & -1.29 & 0.13 & 0.45 & 0.68 & 1.42 & 0.12 \\
\hline
\end{tabular}

Note: $* p<0.05$.

Abbreviation: MMA, multivariate multilevel analysis.

Table 4 Correlations in individual outcomes at the individual level

\begin{tabular}{lllll}
\hline & Physical capacity domain & Psychological domain & Social relationship domain & Environmental domain \\
\hline Physical capacity domain & $\mathrm{I}$ & & & \\
Psychological domain & 0.18 & $\mathrm{I}$ & & \\
Social relationship domain & 0.24 & 0.18 & $\mathrm{I}$ & $\mathrm{I}$ \\
Environmental domain & 0.15 & 0.26 & 0.25 & \\
\hline
\end{tabular}

Table 5 Correlations in individual outcomes at the village level

\begin{tabular}{lllll}
\hline & Physical capacity domain & Psychological domain & Social relationship domain & Environmental domain \\
\hline Physical capacity domain & $\mathrm{I}$ & & & \\
Psychological domain & 0.69 & $\mathrm{I}$ & & \\
Social relationship domain & 0.52 & 0.71 & $\mathrm{I}$ & $\mathrm{I}$ \\
Environmental domain & 0.91 & 0.65 & 0.65 & \\
\hline
\end{tabular}


As Table 4 shows, weak correlations were observed between individual outcome at the second level, and this correlation shows that we did not have a noticeable error in our choice of levels. The pattern of rural variation admitted multilevel modeling and supported using villages as level 3 (Table 5). The results show that in those villages in which the physical capacity of an individual is satisfactory, the environmental domain also receives an acceptable grade $(r=0.9)$.

\section{Discussion}

To the best of our knowledge, the present study is the only attempt to assess the effects of some covariates on a questionnaire's domain score based on MMA. Because WHOQOLBREF does not have a total HRQOL score, and its domain scores are used for assessing HRQOL, ${ }^{3}$ we applied domain scores as four outcome variables.

The mean rating for all domain scores fell between 12.53 and 14.27, indicating that HRQOL scores for rural women were generally acceptable. There has been no study on rural HRQOL based on WHOQOL-BREF precisely that we can compare our results to; nonetheless, in comparison to some other studies, such as the study examining Taiwanese rural people aged more than 65 years, ${ }^{20}$ Iranian rural women had significantly lower HRQOL in the physical capacity $(P<0.0001)$ and environment domains $(P<0.0001)$, but Iranian women scored significantly better in the social relationship domain $(P<0.0001)$ and also in the psychological domain $(P<0.0001)$. This may be due to their nourishment status; the majority of Taiwanese eat large amounts of vegetables, unlike rural Iranians that use mainly dairy products and meat in their daily diet. Better facilities may have led to more environmental satisfaction, especially for Iranian women, because of their sensitivity.

In the social relationships and psychological domains, being close to family, and having emotional support and help creates hope and happiness for rural women. According to an urban study in Tehran, the capital of Iran, with the sample mean age of 36.6 years, rural women had significantly lower scores in physical capacity $(P<0.0001)$, but significantly higher scores in the social relationship domain $(P<0.0005)$ and environmental domain $(P<0.01) .{ }^{11}$ Despite the fact that our sample was younger, their physical capacity was weaker. Proximity to health facilities may allow higher physical capacity in cities, but living in a small rural society and having support from other people leads to social satisfaction. In addition, living in a non-polluted area may be cause for better environmental health. According to the WHOQOL group result that included 24 countries' HQROL scores, our results are relatively similar in the social relationships domain to those 24 countries, but our results score lower in the other three domains. ${ }^{3}$ These findings show that rural women had suitable social relationships overall, but that they need more attention in other domains of HRQOL.

Comparing MA and MMA, some covariates did not show their statistically significant effect in MA, and this result supports the precision of MMA.

Another observation in support the merits of MMA was revealed in the correlation matrices. Despite the strong correlation in rural level between individual outcomes, there is a weak correlation between outcomes at the individual level, and these issues confirm that considering villages as a level in this study was an appropriate decision. What is more interesting, however, is that in the comparison of MA and MMA results, none of the covariates was significant in MA, except chronic illness and age; however, we can observe that marital status was another influential predictor of HRQOL in MMA along with chronic illness, but age did not have a significant effect in this analysis.

These results indicate the precision of MMA in exploring important effects. The findings presented in this paper reveal that specific issues should be addressed by MMA, instead of MA. It seems that education status does not have significant effect on the HRQOL domain score in either analysis, unlike another study. ${ }^{21}$

Unlike another study, which have traditionally shown that age has a significant negative effect on HRQOL scores, ${ }^{3}$ our results did not exhibit this negative effect. In our study, age had a significant influence on physical capacity and psychology domains, according to MA, and this result was completely expectable. MMA did not show any significant linear association between age and the four domain scores. This study had the limitation of not assessing more covariates. In fact, we recorded only some demographic variables among other variables that have influence on HRQOL; also, we used only villages as the sole variable in level 3 .

\section{Conclusion}

Rural women need more attention in their life from government and society, especially in facilities and health. MMA is an ideal method for this type of study in exploring the important covariates in HRQOL, as compared to MA.

\section{Disclosure}

The authors report no conflicts of interest in this work. 


\section{References}

1. Testa MA, Simonson DC. Assessment of quality of life outcomes. N Engl J Med. 1996;334(13):835-840.

2. Ferrans CE, Zerwic JJ, Wilbure JE, Larson JL. Conceptual model of health-related quality of life. J Nurs Scholarsh. 2005;37(4):336-342.

3. Skevington SM, Lotfy M, O'connel KA; WHOQOL Group. The World Health Organization's WHOQOL-BREF quality of life assessment: psychometric properties and results of the international field trial. A report from the WHOQOL Group quality of life research. Qual Life Res. 2004;13(2):299-310.

4. Mojica NM, Gebremedhin GT, Schaeffer PV. Valuing community attributes in rural counties of West Virginia using data envelopment analysis. J Renal Community Dev. 2010;5(3):133-142.

5. Molaei MA, Santhapparaj AS, Malarvizhi CA. Rural migrant's job preference in urban Iran and its determinants. Int J Appl Econ Finance. 2008;2:6-43.

6. Adámek $\mathrm{P}$, Němec $\mathrm{O}$. Kvalita života a realizace principu rovných príležitostí na trhu práce [Quality of life and realization of the equal opportunities principle in the labor market]. Acta Oecon Pragen. 2005;8:8-21. Czech.

7. Pospěch P, Delín M, Spěšná D. Institute of Agricultural Economics and Information, Brno, Czech Republic. Kvalita života na českém venkově [Quality of life in Czech rural areas]. AGRIC ECON-Czech. 2009;6:284-295. Czech. Available from: http://www.agriculturejournals.cz/publicFiles/07901.pdf. Accessed January 16, 2015.

8. Philips D. Quality of Life: Concept, Policy and Practice. Oxon: Taylor \& Francis Group. March 2006.

9. Zaid YA, Popoola SO. Quality of life among rural Nigerian women: the role of information. Library Philosophy Practice. 2010:1-12. Available from: http://www.indexmundi.com/facts/iran/rural-population. Accessed January 29, 2015.

10. Nedjat S, Montazeri A, Holakouie K, Mohammad K, Majdzadeh R. Psychometric properties of Iranian interview-administered version of World Health Organization's Quality of Life Questionnaire (WHOQOLBREF): a population-based study. BMC Health Serv Res. 2008;8:61.

11. Lim JT, Park JH, Lee JS, Oh J, Kim Y. The relationship between the social network of community-living elders and their healthrelated quality of life in Korean province. J Prev Med Public Health. 2013;46(1):28-38.
12. Liu N, Zeng L, Li Z, Wang J. Health-related quality of life and long-term care needs among elderly individuals living alone: a crosssectional study in rural areas of Shaanxi Province, China. BMC Public Health. 2013;13:313.

13. Liu N, Zeng L, Li Z, Wang J. Health-related quality of life and long-term care needs among elderly individuals living alone: a cross- sectional study in rural areas of Shaanxi Province, China. BMC Public Health. 2013;313:1-7.

14. Yousefy AR, Ghassemi GR, Sarrafzadegan N, Mallik S, Baghaei AM, Rabiei K. Psychometric properties of the WHOQOL-BREF in an Iranian adult sample. Community Ment Health J. 2010;46(2):139-147.

15. Kent EE, Sender LS, Morris RA, et al. Multilevel socioeconomic effects on quality of life in adolescent and young adult survivors of leukemia and lymphoma. Qual Life Res. 2013;22(6):1339-1351.

16. WHOQoL Group. Development of the World Health Organization WHOQoL-BREF quality of life assessment. Psycho Med. 1998;28(3): 551-559.

17. World Health Organization Division of Mental Health. Summary of Analyses of WHOQOL Pilot Data. Geneva: World Health Organization; 1995. Available from: http://www.who.int/mental_health/ who_qol_field_trial_1995.pdf. Accessed January 29, 2015.

18. Browne W, Rasbash J. Multilevel modeling. In: Hardy M, Bryman A, editors. Handbook of Data Analysis. London: Sage Publications; 2004:459-478.

19. Leeuw JD, Meijer E. Handbook of Multilevel Analysis. Springer, NY, USA; 2008. Available from: http://faculty.udesa.edu.ar/WalterSosa/ multinivel/Handbook.pdf. Accessed January 16, 2015.

20. Liang WM, Chang $\mathrm{CH}$, Yeh YC, Shy HY, Chen HW, Lin MR. Psychometric evaluation of the WHOQOL-BREF in communitydwelling older people in Taiwan using Rasch analysis. Qual Life Res. 2009;18(5):605-618.

21. Chang CY, Hung CK, Chang YY, Tai CM, Lin JT, Wang JD. Healthrelated quality of life in adult patients with morbid obesity coming for bariatric surgery. Obes Surg. 2010;20(8):1121-1127.
International Journal of Women's Health

\section{Publish your work in this journal}

The International Journal of Women's Health is an international, peerreviewed open-access journal publishing original research, reports, editorials, reviews and commentaries on all aspects of women's healthcare including gynecology, obstetrics, and breast cancer. The manuscript management system is completely online and includes

\section{Dovepress}

a very quick and fair peer-review system, which is all easy to use Visit http://www.dovepress.com/testimonials.php to read real quotes from published authors. 